\title{
Postmetamorphic Cell Death in the Nervous and Muscular Systems of Drosophila melanogaster
}

\author{
Ken-ichi Kimura ${ }^{a}$ and James W. Truman \\ Department of Zoology, University of Washington, Seattle, Washington 98195
}

\begin{abstract}
Programmed cell death occurs in the nervous and muscular system of newly emerged adult Drosophila melanogaster. Many of the abdominal muscles that were used for eclosion and wing-spreading behavior degenerate by $12 \mathrm{hr}$ after eclosion. Related neurons in the ventral ganglion also die within the first $24 \mathrm{hr}$. Ligation experiments showed that the muscle breakdown is triggered by a signal from the anterior region, presumably the head, that occurs about $1 \mathrm{hr}$ before adult emergence. The timing of this signal suggests that eclosion hormone may be involved. Although muscle death is triggered prior to ecdysis, it can be delayed, at least temporarily, by forcing the emerging flies to show a prolonged ecdysis behavior. In contrast to the muscles, the death of the neurons is triggered after emergence. The signal for neuronal degeneration is closely correlated with the initiation of wing inflation behavior. Ligation and digging experiments and behavioral manipulations that either blocked or delayed wing expansion behavior had a parallel effect in suppressing or delaying neuronal death.
\end{abstract}

Cell death is a common feature of developing nervous systems of many vertebrates (Hamburger and Oppenheim, 1982; Williams and Herrup, 1988) and invertebrates (Truman, 1984). Depending on the particular system, neuronal death is regulated by various factors, the most common being interactions with targets (Hamburger, 1975; O'Leary et al., 1986) and hormones (Truman and Schwartz, 1984; Nordeen et al., 1985). Despite advances in understanding the factors that control neuronal survival and death in these various systems, relatively little is known about the molecular events that lead to the death of the cells in question. Studies using inhibitors of macromolecular synthesis have provided some insight into the nature of some of these early events. Treatment with these drugs has been shown to depress the degeneration of motoneurons and dorsal root ganglion cells in embryonic chick spinal cord (Oppenheim and Prevette, 1988), to block the death of cultured embryonic sympathetic ganglion neurons resulting from nerve growth factor deprivation (Martin et al., 1988), and to prevent the postmetamorphic death in moths of both muscles (Lockshin, 1969; Schwartz and Kay, 1987) and motoneurons (Fahrbach and Truman, 1988). Thus, in these diverse systems, cell death appears to be an active process that requires that the doomed cell un-

Received Apr. 19, 1989; revised Aug. 16, 1989; accepted Aug. 22, 1989.

This work was funded by NIH grant R01 NS 13079.

Correspondence should be addressed to Dr. James $W$. Truman at the above address.

"Present address: Laboratory of Biology, Hokkaido University of Education, Iwamizawa, Iwamizawa 068, Japan.

Copyright (C) 1990 Society for Neuroscience $0270-6474 / 90 / 100403-09 \$ 02.00 / 0$ dertake the synthesis of new RNAs and proteins. The most progress toward understanding the nature of these genes that mediate cell degeneration has come from a genetic approach in the nematode Caenorhabdites elegans. In particular, 2 genes have been isolated, cell death (ced) 3 and ced 4, whose wildtype product is required in order for the doomed cells to die (Hedgecock et al., 1983; Ellis and Horvitz, 1986).

Insects that go through metamorphosis show the death of selected muscles and neurons immediately after the emergence of the adult (Finlayson, 1975; Truman, 1983). A number of large moths, in particular the tobacco hornworm, Manduca sex$t a$, are especially amenable to physiological studies and have provided information about the hormonal and neural factors that initiate this cell death (Schwartz and Truman, 1982, 1983; Truman and Schwartz, 1984; Fahrbach and Truman, 1987). These moths, however, are not suitable for the type of genetic approach that has been used in the nematode. Consequently, we have turned to the fruitfly, Drosophila melanogaster, to explore the genetic and molecular aspects of cell death. This insect shows extensive death of head and abdominal muscles after the emergence of the adult fly (Atkins, 1949; Miller, 1950). Also, 2 mutants have recently been isolated which delay the degeneration of certain of these head muscles that are normally doomed to a rapid death (K.-i. Kimura and T. Tanimura, unpublished observations). The fly lacks, however, information on the extent of neuronal death that occurs after metamorphosis and the nature of the signals that might trigger the death of the neurons and muscles. This information is the basis of this paper and provides a background that will facilitate future genetic studies.

\section{Materials and Methods}

Flies. The fruit flies, Drosophila melanogaster, were reared on cornmealyeast medium at $25^{\circ} \mathrm{C}$ under constant illumination. Males and females from a Canton-Special strain were used for experiments. To obtain insects that were just before adult emergence (pharate adults), we collected puparia that contained developing adults whose bristles had already turned black. These were lined up on a strip of double-stick tape attached to a glass slide. The operculum was removed from each puparium to facilitate observations of the developing adult, and the insects were then kept in an enclosed, moist Petri dish. Animals were staged under a dissection microscope according to features of the head, as described in Results.

Observation of the fate of the muscles. The muscles of the abdomen were examined using whole-mount preparations. The abdomens were dissected in saline solution (Ephrussi and Beadle, 1936). Gut, crop, and Malpighian tubules were cut away and the larval fat bodies removed with gentle pipetting. Abdomens were stained with a $1 \%$ toluidine blue solution in borax buffer ( $\mathrm{pH}$ 7.4) (Altman and Bell, 1973) for 15-30 min. They were then fixed and destained in Bodian's fixative $(5 \mathrm{ml}$ formalin, $6 \mathrm{ml}$ glacial acetic acid, $90 \mathrm{ml} 80 \%$ ethanol), dehydrated, cleared in methylsalicylate, and mounted in Canada balsam. Muscles were examined using normal and polarizing light optics. The state of 


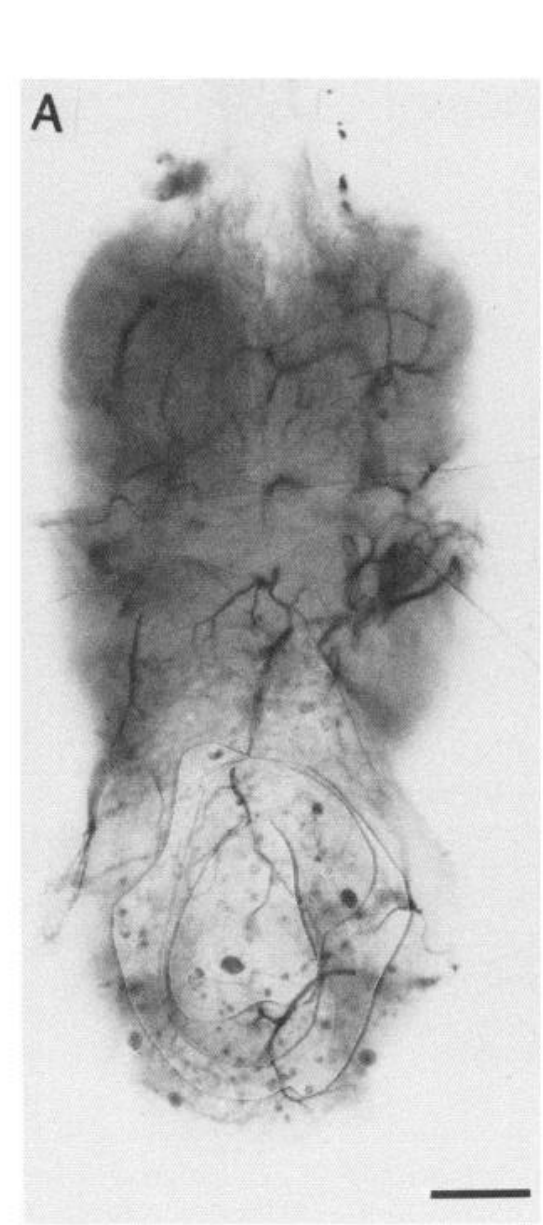

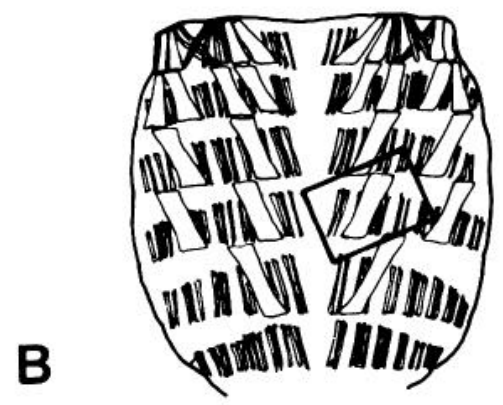
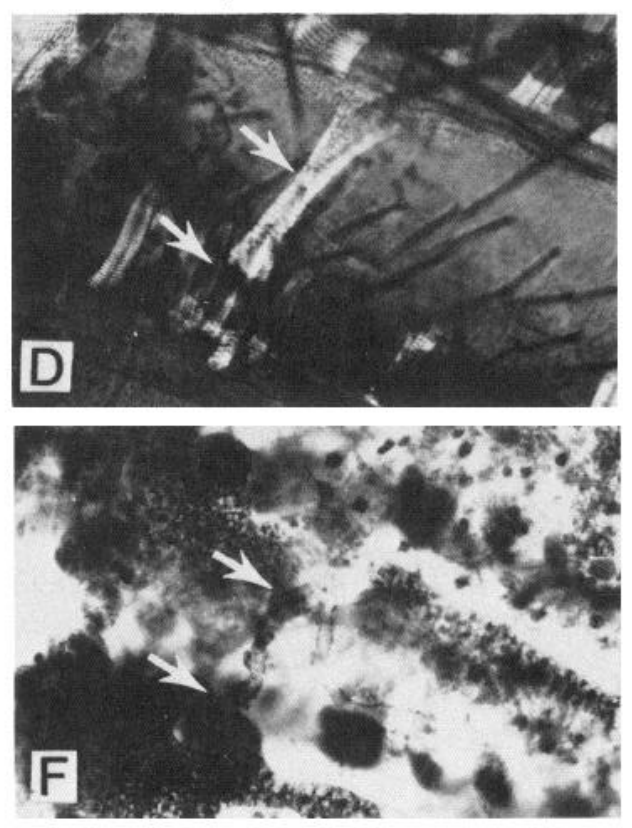
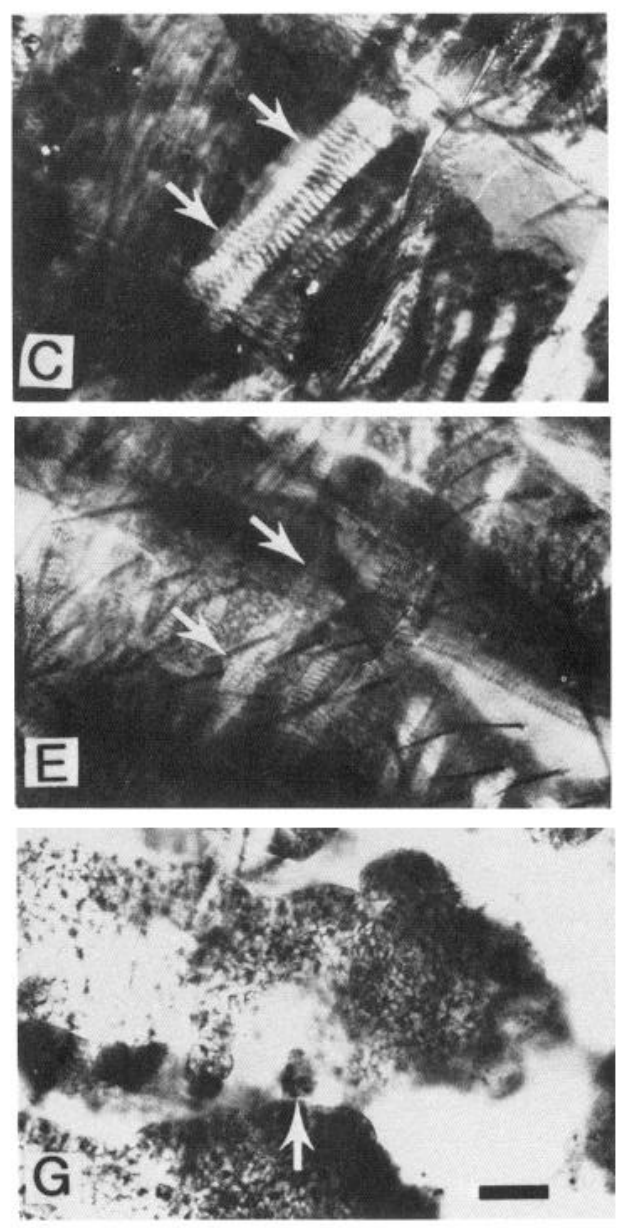

Figure 1. A, Dorsal view of the fused ventral ganglia $8 \mathrm{hr}$ after eclosion stained with toluidine blue. Dying cells have an elliptical profile and occur in the posterior region of the CNS. B. Diagram of muscles on the dorsal tergites of the abdomen at $0 \mathrm{hr}$ after eclosion. Square represents the location of $C-G$. $C-G$, Shows polarizing microscopy $(C, D, E)$ and light microscopy $(F, G)$, showing stages of the muscle breakdown of the medial DIOM (arrows) in the fourth segment. $C$, Stage $5 ; D$, stage $4 ; E$, stage $3 ; F$, stage $2 ; G$, stage 1 . For descriptions of the stages, see text. Scale bars, $50 \mu \mathrm{m}$.

muscle breakdown was divided into 5 stages as indicated for the dorsal internal oblique muscle (DIOM) in the fourth segment (Fig. 1). Stage 5 fibers showed normal striations and the width of the center of the fiber was more than $30 \mu \mathrm{m}$. The fiber width was reduced (width $<30 \mu \mathrm{m}$ ) but striations were still present in stage 4 . In stage 3 , the fiber lost its striations and its birefringence was weak. In stage 2 , the fiber became wavy and sometimes showed pyknotic nuclei. In stage 1 , the fibers disappeared, although sometimes remnants of the fiber could still be seen (Fig. $1 G$, arrow). The stage of muscle breakdown was determined for both DIOMs and the mean was calculated for each preparation.

Observation of neuronal death. We modified the method of Spreij (1971) to stain dying cells. The fly was injected with a $0.1 \%$ toluidine blue solution in saline using a glass capillary needle connected to a microinjector. Flies, anesthetized with $\mathrm{CO}_{2}$, were injected through the abdominal pleura and given enough dye to fully expand the abdomen. The injected flies were left for 15-30 $\mathrm{min}$ in a moist Petri dish, and the ventral ganglion was then dissected out in saline solution. The living ganglion was mounted on a glass slide and examined with a light microscope. Dying cells did not exclude the dye and were stained a violetblue color (Fig. 1A). The position of the staining cells was drawn using a drawing tube. The number of large (diameter of cell $>5 \mu \mathrm{m}$ ) staining cells was counted.

Ligation of animals. Flies were ligated at the neck or between thorax and abdomen with a thin silk thread and the anterior body was cut away. The pupal case was removed from around the head or thorax before the ligation, but the remainder of the pupal case was left intact. Neck-ligatured animals in the "white" and "extended ptilinum" stages often shed the pupal case after ligation. The ligated flies were then kept in a moist Petri dish. Neck-ligated flies survived for several days; the isolated abdomens were not as viable and did not live for quite as long.

\section{Results}

\section{Development of the pharate adult in Drosophila}

Under our conditions, female Drosophila required $94.8 \pm 1.8$ $\mathrm{hr}$ (mean $\pm \mathrm{SD}, n=30$ ) from the start of metamorphosis, at the formation of the white puparium, to the eclosion of the adult, and males took $101.2 \pm 1.4 \mathrm{hr}(n=30)$. The changes during the last $10 \mathrm{hr}$ of adult development could be divided into 7 stages, the timing of which varied slightly with sex (Table 1). At about 9-10 hr before eclosion, the meconium which had appeared at a dorsal anterior site of the abdomen moved to reach the posterior tip [stage P14(44) in Bainbridge and Bownes, 1981]. At this time, the space between the pupal and adult cuticles was filled with molting fluid and the pupal cuticle of the head had a smooth appearance [smooth (S) stage]. After about $3 \mathrm{hr}$, wrinkles appeared in the pupal cuticle over the head [smooth/grainy (S/G) stage] because of the initiation of resorption of the molting fluid. By about $3 \mathrm{hr}$ before eclosion, molting fluid resorption was well advanced and the pupal cuticle had a granular appearance [grainy (G) stage]. The transition between the $S / G$ and $G$ stages was gradual and hard to pinpoint. At about 

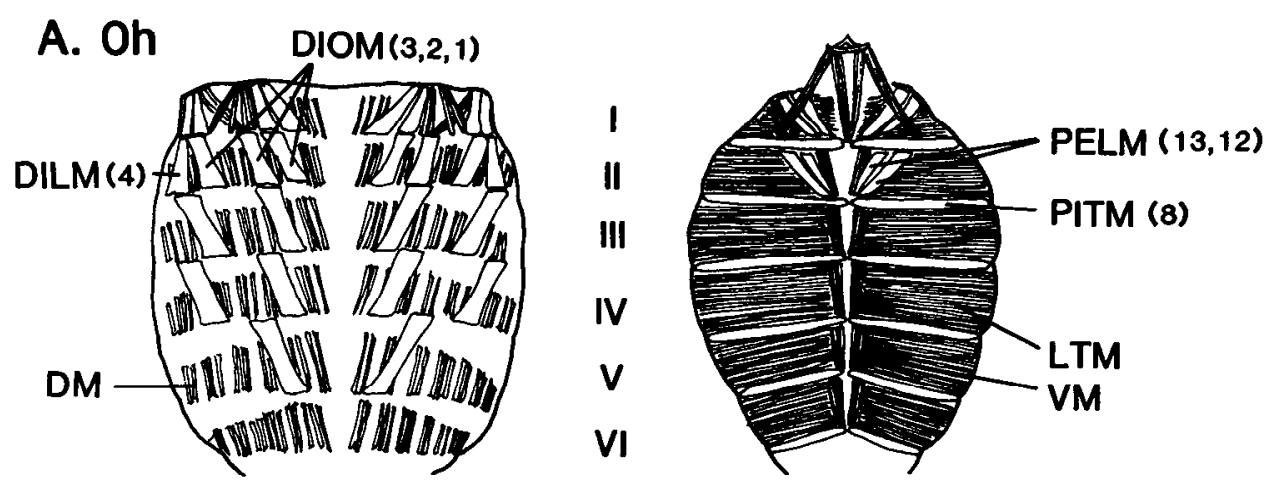

\section{B. $24 \mathrm{~h}$}

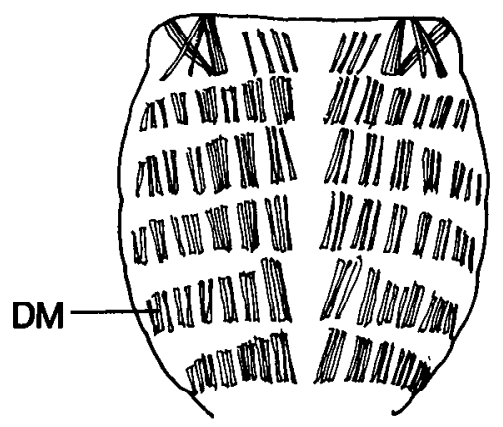

Dorsal

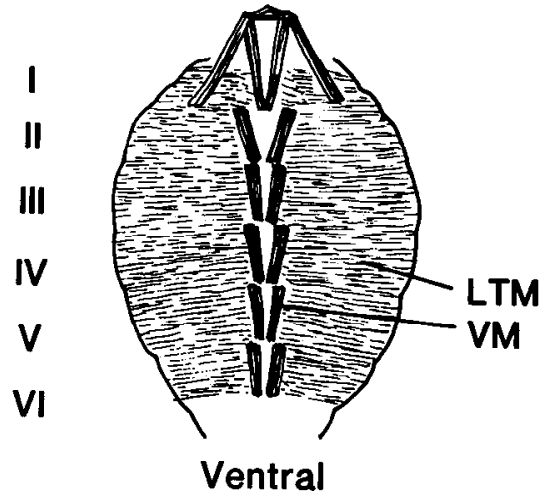

Figure 2. Abdominal musculature of an adult female fly at $0 \mathrm{hr}(A)$ and at 24 $\mathrm{hr}(B)$ after eclosion. Dorsal view (left) of tergites and ventral view (right) of pleura and sternites. Roman numerals in the center represent the scgments of the abdomen. For abbreviations of muscle names, see text.
$50 \mathrm{~min}$ before eclosion, air filled the trachea of the head and a pair of white spots appeared between eyes [grainy/white $(G / W)$ stage]. A few minutes later, the space between the pupal and adult cuticles became completely filled with air and the head and body acquired a whitish sheen [white (W) stage]. The ptilinum was then gradually protruded from the front of the head, thereby rupturing the thin pupal cuticle [extended ptilinum (EP) stage]. After about $40 \mathrm{~min}$ in males and $30 \mathrm{~min}$ in females, the flies then eclosed [eclosion (E) stage].
Muscle breakdown and neuronal death after eclosion

The muscles in the abdomen of newly eclosed flies show 2 types of fates: some degenerate soon after eclosion while others persist through adult life (Fig. 2). Muscles exhibiting the first fate come from larval muscles that had survived through metamorphosis, while the persistent muscles are ones that are newly formed during metamorphosis (data not shown). The terminology and numbers are adapted from a description of larval musculature

Table 1. Developmental events of a pharate adult in Drosophila melanogaster

\begin{tabular}{|c|c|c|c|}
\hline \multirow[b]{2}{*}{ Stage } & \multicolumn{2}{|l|}{ Time $(\mathrm{hr})^{a}$} & \multirow[b]{2}{*}{ Events } \\
\hline & Male & Female & \\
\hline Smooth (S) & $-9.8 \pm 1.1$ & $-8.7 \pm 1.6$ & $\begin{array}{l}\text { Surface of a head is smooth; molting fluid remains } \\
\text { between pupal and adult cuticle }\end{array}$ \\
\hline $\begin{array}{l}\text { Smooth/grainy } \\
(\mathrm{S} / \mathrm{G})\end{array}$ & $-7.0 \pm 1.0$ & $-5.7 \pm 0.9$ & $\begin{array}{l}\text { Wrinkles appear at pupal cuticle; molting fluid is } \\
\text { being resorbed }\end{array}$ \\
\hline Grainy $(G)$ & $-3.0 \pm 0.6$ & $-2.8 \pm 0.5$ & $\begin{array}{l}\text { Surface of head is grainy; most molting fluid has } \\
\text { been resorbed }\end{array}$ \\
\hline $\begin{array}{l}\text { Grainy/white } \\
(\mathrm{G} / \mathrm{W})\end{array}$ & $-0.9 \pm 0.1$ & $-0.9 \pm 0.1$ & $\begin{array}{l}\text { Trachea, which is filled with air, appears white } \\
\text { between eyes }\end{array}$ \\
\hline White (W) & $-0.8 \pm 0.1$ & $-0.8 \pm 0.1$ & $\begin{array}{l}\text { Fly appears white because of air between pupal and } \\
\text { adult cuticle }\end{array}$ \\
\hline $\begin{array}{l}\text { Extended- } \\
\text { ptilinum (EP) }\end{array}$ & $-0.7 \pm 0.2$ & $-0.6 \pm 0.2$ & Fly extends the ptilinum and ruptures pupal cuticle \\
\hline Eclosion (E) & 0 & 0 & Start of eclosion \\
\hline
\end{tabular}




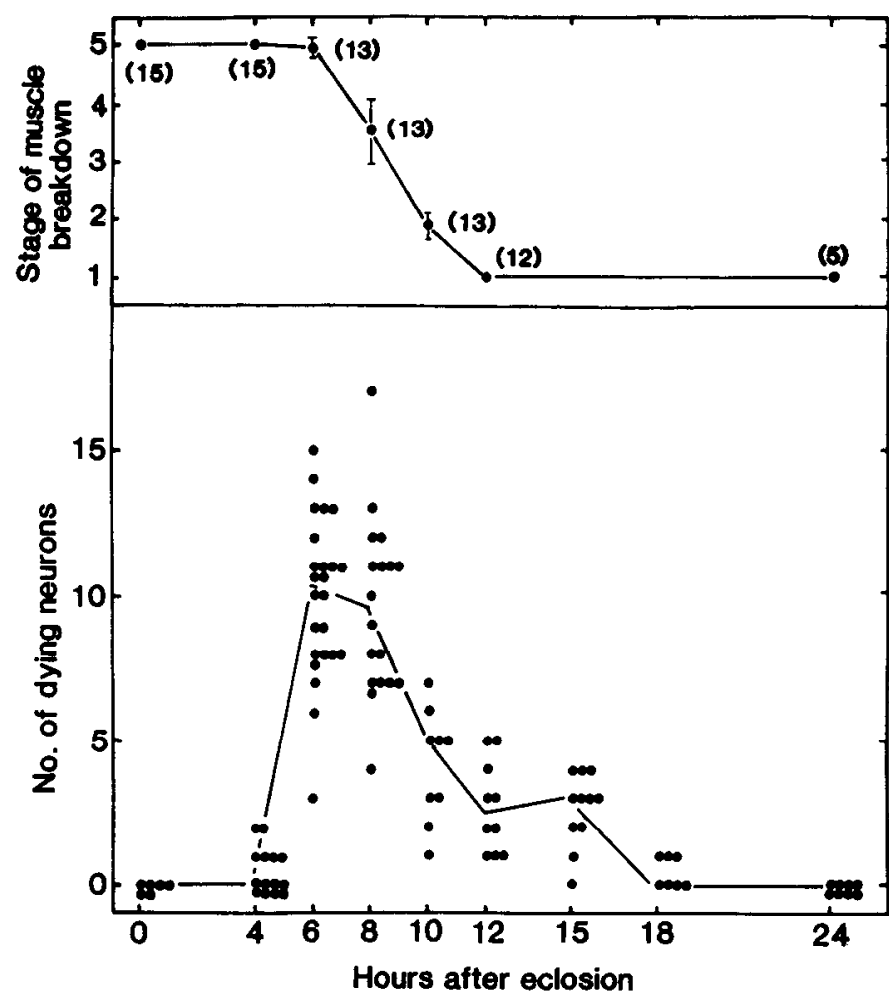

Figure 3. Time course of the muscle breakdown (top) and the neuronal death (bottom) of the intact flies after eclosion. Top, Each point represents the mean $( \pm \mathrm{SD})$ score of the degeneration of the medial DIOM in the 4 th segment. Numbers beside the points are counts of flies examined. Bottom, Each point represents the number of large (diameter of cell body $>5 \mu \mathrm{m}$ ) dying neurons in a fused ventral ganglion. Solid line was drawn through the median values.

by Crossley (1978) for the first type of muscles and from a description of adult musculature by Miller (1950) for the second type.

The doomed muscles show segmental differences in their distribution. The first and second segments of the abdomen have 3 pairs of DIOMs (1, 2, and 3), onc pair of dorsolateral internal longitudinal muscles (DILM 4), and 2 pairs of pleural external longitudinal muscles (PELM 12 and 13). The third and fourth segments have 2 pairs of DIOM (1 and 3) but not DILM or PELM. The fifth segment has only 1 pair of DIOM (1) and the six th segment has no doomed muscles. A pair of pleural internal transverse muscles (PITM 8) between each segment also dies after eclosion. The patlern of the doomed muscles was somewhat variable and newly eclosed flies sometimes lacked one or more of these groups.

The dorsal muscles (DM) and ventral muscles (VM) in each segment persist through adult life. The DMs comprise about 15 longitudinal fibers on each hemitergite and the VMs consist of about 6 fibers on each hemisternite. The lateral tergosternal muscles (LTM) include about 20 fibers that cover the pleura of each segment. They also persist during adult life but become thinner and their birefringence decreases after eclosion. A few pairs of extra muscles also occur in the first segment. Additionally, a male fly has a pair of male-specific muscles beside DIOM in the fifth segment (Lawrence and Johnston, 1984).

The time course and pattern of muscle breakdown were examined using DIOM 1 in the fourth segment for reference (Fig. 3). The pattern of the muscle breakdown was divided into 5 stages as described in Materials and Methods. Until $4 \mathrm{hr}$ after eclosion, the muscles showed no morphological changes as distinguished in whole mounted preparations at the light microscopic level (stage 5). The muscles began to become thinner by $6 \mathrm{hr}$, but they retained good striations (stage 4). There then followed the disappearance of the striations and a weakening of the birefringence (stage 3). After $10 \mathrm{hr}$, the remains of the muscles had become flaccid and sometimes contained pyknotic nuclei (stage 2). The fibers then fragmented and were rapidly absorbed. By 12 hr most fibers had disappeared (stage 1).

Neuronal death occurred in the ventral ganglion after eclosion. Figure 4 shows the distribution of the dying cells at various times after eclosion as revealed by staining living ganglia with toluidine blue. Most neuronal death occurred in the dorsal and lateral regions of the abdominal and metathoracic neuromeres, although a few small dying cells were also observed in both the anterior and ventral regions of the fused ganglia. Based on their location and size, many of the large dying cells were presumed to be motoneurons that innervate the doomed muscles in the abdomen. As seen in Figures 3 and 4, the large degenerating neurons were first evident at $4 \mathrm{hr}$ after eclosion. Dying cells reached their maximum abundance at $6-8 \mathrm{hr}$ and then decreased such that none were evident by $24 \mathrm{hr}$.

\section{Effects of ligation experiments on muscle breakdown}

We used ligation techniques to determine possible cues for the breakdown of the abdominal muscles. Blood-tight ligatures were placed between the thorax and abdomen at various stages prior to eclosion, and the fate of DIOM 1 in the fourth segment was then ascertained at $24 \mathrm{hr}$ after ligation (Fig. 5). The earliest time that animals were ligated was the S stage, which is $9 \mathrm{hr}$ before eclosion and about $21 \mathrm{hr}$ before the muscles disappear. Isolated abdomens from these animals retained a full set of contractile muscles when examined $24 \mathrm{hr}$ later and, indeed, the muscles persisted for as long as the abdomens survived (generally a few days). Similarly, abdomens isolated up to the $\mathrm{G}$ stage retained their muscles, but after this time (the W stage or later), the muscles broke down on schedule despite the ligation. These results suggest that muscle breakdown is induced by some signal that comes from the anterior end of the insect $1-3 \mathrm{hr}$ before eclosion.

When ligatures were placed between the head and thorax (Fig. 5), the critical stage at which the ligation affected the muscle breakdown was less clear than for the abdomen-ligation group. By the W stage, the muscles consistently underwent degeneration after ligation. At earlier stages, however, some death was seen despite the ligation; more than half of the flies showed muscle breakdown after ligation at the $G$ stage and a significant percentage even after ligation at the $\mathrm{S} / \mathrm{G}$ stage. Those ligated at $\mathrm{S}$ stage did not show any muscle breakdown within $24 \mathrm{hr}$. The difference in the effects of neck ligation versus abdomen ligation is discussed below.

Elimination of the influence from the head even at the S stage did not completely block muscle degeneration. Figure 6 shows the time course of muscle degeneration after neck ligation at the $\mathrm{S}$ stage. In this series, a few neck-ligated flies had begun muscle breakdown by $24 \mathrm{hr}$ after ligation. Degeneration then proceeded in a similar fashion to that of the intact flies except for the last steps of fragmentation and absorption (from stage 2 to 1). These occur rapidly in intact flies but were gradual and delayed in the ligated preparations. Even at $72 \mathrm{hr}$ after ligation, 

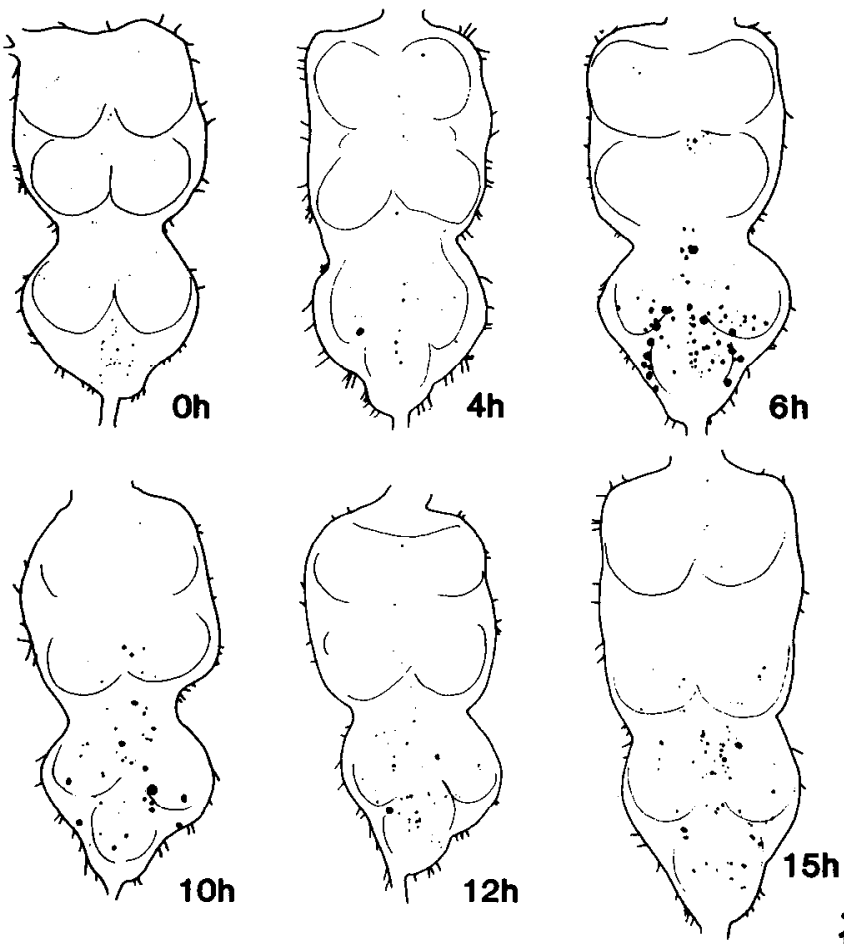

$12 \mathrm{~h}$
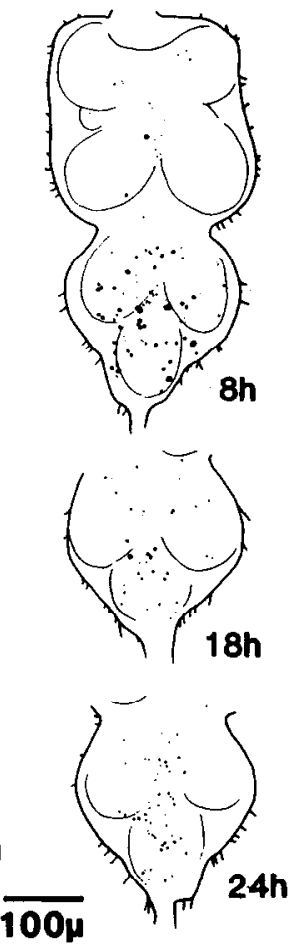

Figure 4. Camera lucida drawings of the fused ventral ganglia showing the distribution of dying cells at various hours after eclosion. Lines within the ganglia indicate the lateral boundaries of the neuropil. fibers having pyknotic nuclei (stage 2) were evident in half of the ligated individuals.

\section{Effects of ligation on neuronal death}

To examine whether neuronal death was also affected by signals coming around eclosion, we ligated the necks of flies at various times after emergence and then monitored the time course of neuronal death. Neck ligation of newly eclosed flies altered the subsequent pattern of neuronal death (Fig. 7A). Degeneration was markedly suppressed although it was not completely prevented. By contrast, when flies were ligated at $1 \mathrm{hr}$ after eclosion, the normal pattern of cell death was then observed (Fig. $7 B$ ). Thus, we concluded that some event during the first hour after eclosion was necessary to trigger the normal time course of death. Newly emerged adult Drosophila show specific posteclosion behavioral and endocrine events during this period. After eclosing from the puparial case, the fly walks briefly, shows occasional cleaning bouts, and then begins to inflate its wings. Cuticular hardening and darkening begins soon thereafter. We collected flies within $15 \mathrm{~min}$ after eclosion and ligated their necks. None had yet begun to inflate their wings at the time of ligation, but after the ligation, some flies subsequently inflated

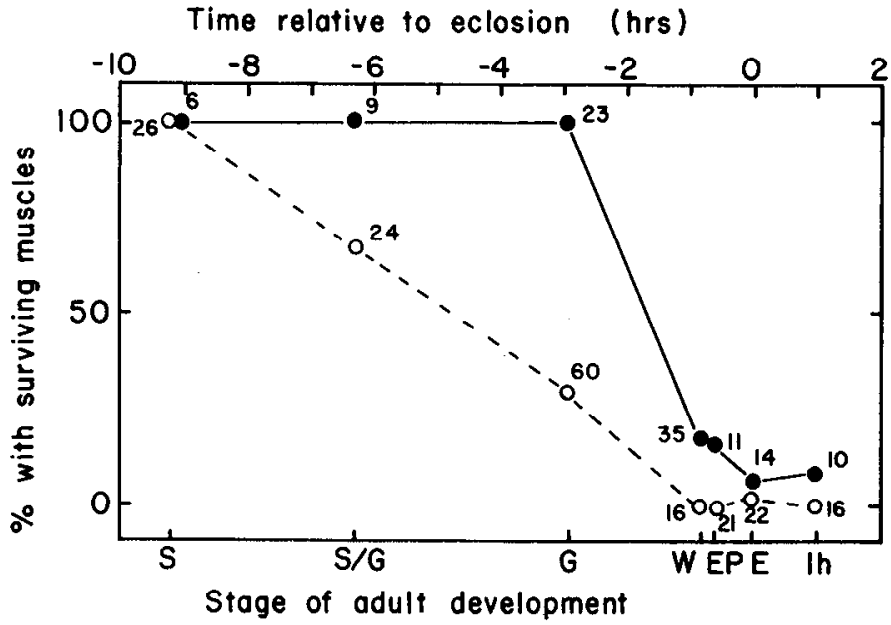

Figure 5. Effect of ligation at the neck $(0)$ or between the thorax and the abdomen (0) on muscle breakdown. Flies were ligated at various stages before and after eclosion and examined $24 \mathrm{hr}$ after ligation to determine the presence of the medial DIOM in the 4th segment. Numbers beside the points represent counts of flies examined. For abbreviations of stages, see Table 1 .

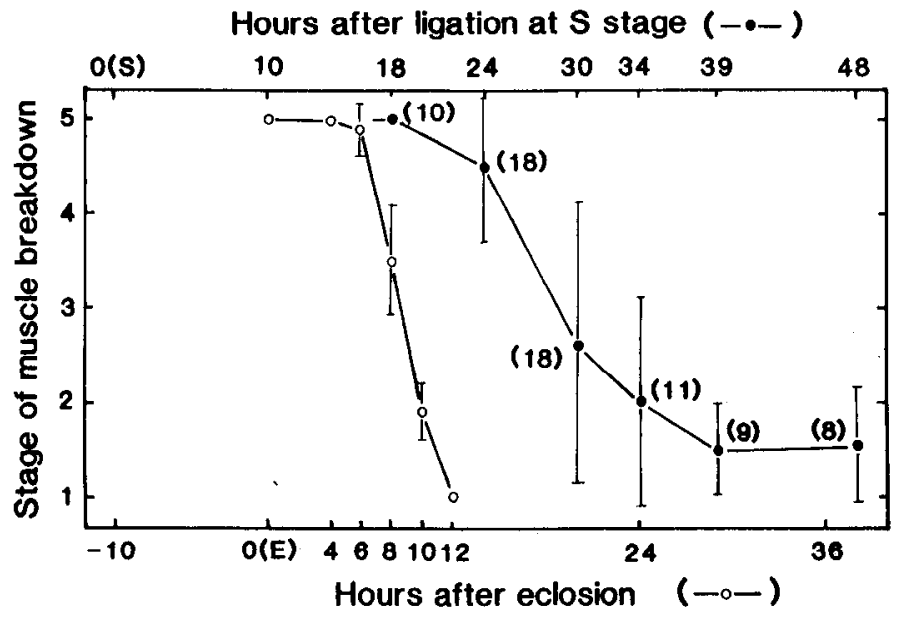

Figure 6. Comparison of the time course of muscle breakdown in control flies $(O)$ and animals neck-ligated at the S stage (O). Each point represents the mean $( \pm S D)$ score of the breakdown of the medial DIOM in the 4th segment. Numbers beside the points are counts of flies examined. 


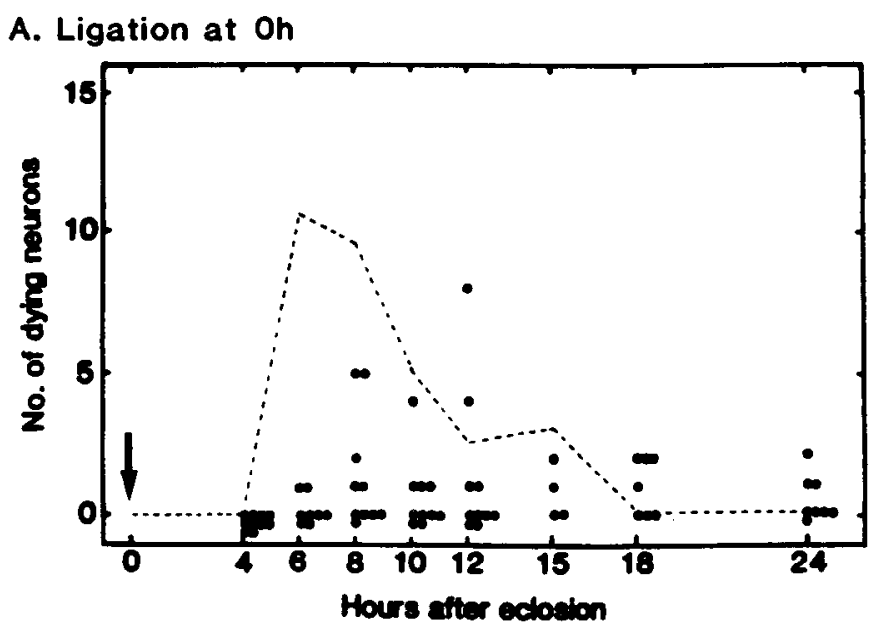

B. Ligation at $1 \mathrm{~h}$

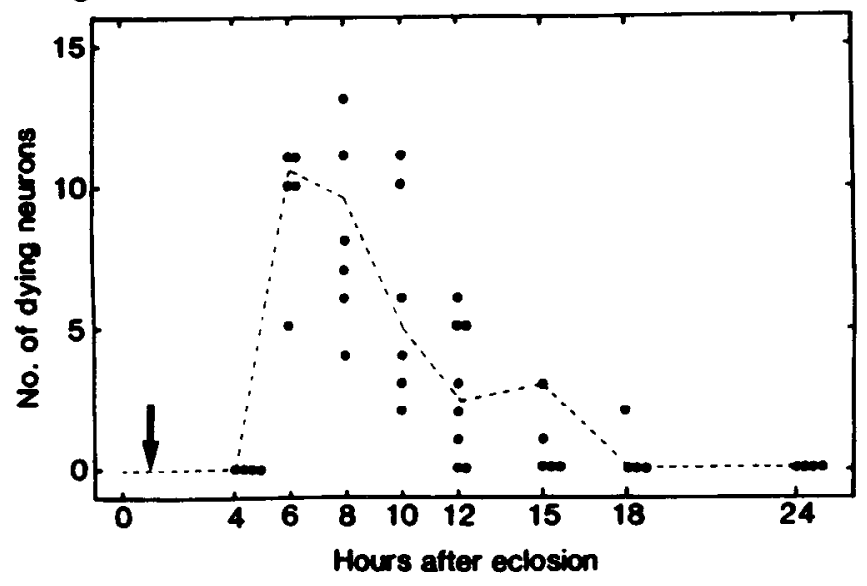

C. Ligation within $15 \mathrm{~min}$

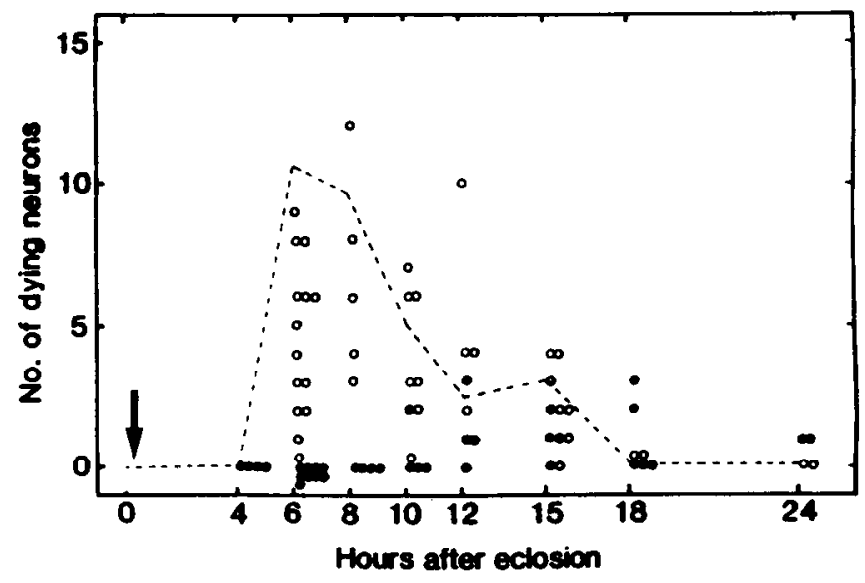

Figure 7. Time course of neuronal death in flies that had been neckligatured at various times after eclosion. Each point represents the number of large $(>5 \mu \mathrm{m})$ dying neurons in a fused ventral ganglion. $A$, Ligation at eclosion $(0 \mathrm{hr}) ; B$, ligation $1 \mathrm{hr}$ after eclosion; $C$, ligation $15 \mathrm{~min}$ after eclosion. Flies in $A$ and $C$ (closed circles) did not inflate their wings after ligation; the other flies either inflated them prior to the ligation $(B)$ or after the ligation $(C$, open circles). Dashed line is based on time course of the neuronal death of intact flies.

their wings and/or tanned their cuticle while others did not. We then examined the ventral ganglion of these flies at $6 \mathrm{hr}$ after eclosion (= ligation) (Table 2). Ligated flies that showed neither wing inflation nor tanning also had no dying neurons. By con-
Table 2. Correlation between the neuronal death and the event of wing spreading and/or tanning of cuticle

\begin{tabular}{llll} 
Wing & & $\begin{array}{l}\text { Percent of } \\
\text { flies } \\
\text { showing } \\
\text { large } \\
\text { dying } \\
\text { neureading }\end{array}$ \\
\hline- & Tanning & $\begin{array}{l}\text { No. of flies } \\
\text { examined }\end{array}$ & $\begin{array}{l}\text { neurons } \\
-\end{array}$ \\
$+^{\prime \prime}$ & - & 9 & 18 \\
& $+^{a}$ & 11 & 94
\end{tabular}

The flies were ligated at the neck within $15 \mathrm{~min}$ after eclosion and the number of large dying neurons was counted $6 \mathrm{hr}$ later.

"Includes flies whose cuticle was tanned fully or partially at $6 \mathrm{hr}$ after eclosion.

"Includes flies that expanded their wings fully or partially at $6 \mathrm{hr}$ after eclosion.

trast, those that both inflated their wings and tanned showed at least some dying cells. We also observed 11 flies that underwent normal tanning but did not inflate their wings. Nine of these showed no dying neurons. Consequently, the neuronal death is correlated with the behavior of wing inflation rather than with the tanning of cuticle.

A larger group of flies were ligated within 15 min after eclosion and then examined at various times thereafter to establish the time course of death in the 2 groups (Fig. $7 \mathrm{C}$ ). Those that subsequently inflated their wings showed a time course of neuronal death that was similar to that of intact flies. Those that did not show the behavior had only a suppressed level of degeneration.

\section{Behavioral modification of neuronal and muscle death}

In large flies, Sarcophaga (Cottrell, 1962) and Calliphora (Fraenkel, 1935) and in the moth, Manduca sexta (Truman, 1973), the events after eclosion, such as wing-spreading behavior, can be modified or delayed by forcing the insect to dig. In Drosophila melanogaster, flies do not normally dig after eclosion in laboratory culture conditions since pupariation occurs out of the medium. However, if such flies are confined, they continue to show eclosion movements (which also serve for digging) and delay wing inflation behavior. We forced newly eclosed flies to dig by confining them in an empty puparial case. This was accomplished by placing the open end of an empty case in front of the eclosing fly. After entering into the case, the insect could not turn around and it showed sustained eclosion/digging behavior for several hours.

We examined the effect of this confinement on both neuronal and muscle death. When the flies were forced to dig for $2 \mathrm{hr}$ and then released from the case, most of them $(>80 \%)$ subsequently inflated their wings completely or partially, and their neuronal death was normal in pattern but delayed by $2 \mathrm{hr}$ (Fig. $8 A$ ). When flies were confined continuously in the pupal case, wing inflation behavior did not occur and neuronal death was suppressed (Fig. $8 B$ ). Thus, either the sustained digging/eclosion behavior of the confined fly directly suppresses the neuronal death or the confinement prevents the performance of subsequent behaviors, such as wing inflation hehavior, which are the triggers for the degeneration.

Confinement also modified the time course of muscle breakdown. Two hours of confinement delayed muscle breakdown by about $2 \mathrm{hr}$ (Fig. $8 A$ ). In the flies that were confined continuously, however, the muscle breakdown was not further delayed (Fig. $8 B$ ). Thus, muscle degeneration, which is triggered by a 

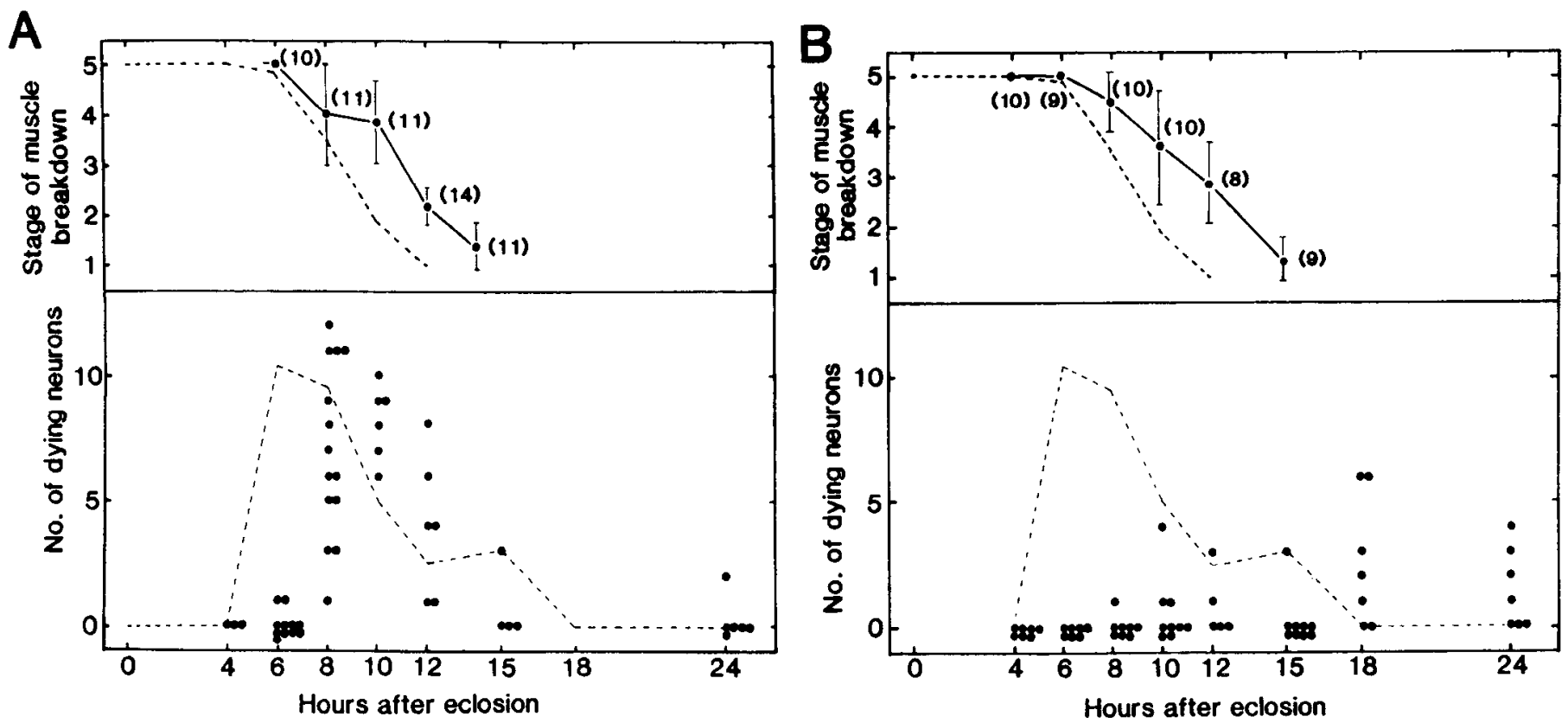

Figure 8. Modification of the time course of the muscle breakdown (top) and of neuronal death (bottom) by digging behavior after eclosion. $A$, Flies were confined in the pupal cases for $2 \mathrm{hr}$ after eclosion and then freed. $B$. Flies were confined continuously in the pupal cases after eclosion. $T o p$, Each point represents the mean $( \pm \mathrm{SD})$ score of the breakdown of the medial DIOM in the 4 th segment. Numbers beside the points are counts of flies examined. Bottom, Each point represents the number of large $(>5 \mu \mathrm{m})$ dying neurons in the ventral ganglion. Dashed lines are based on the time course of the muscle breakdown and of neuronal death in intact flies.

signal prior to cclosion, can also be influenced by extrinsic factors after eclosion, but only for a limited period of time.

\section{Discussion}

The final steps in metamorphosis involve the emergence of the adult, expansion of the adult cuticle, and cuticular hardening and darkening. Programmed cell death features prominently at this time as the insect then discards muscles and neurons that were specialized for eclosion and wing inflation behaviors. The hormonal regulation of postecdysial death of muscles has been studied in the Lepidoptera and falls into two patterns. In $M$. sexta, the decline in circulating levels of the steroid hormones, the ecdysteroids, just prior to adult eclosion induces muscle breakdown after emergence of the adult (Schwartz and Truman, 1983). The control in the giant silkmoth, Antheraea polyphemus, is more complex in that muscle breakdown occurs in 2 phases with an initial slow atrophy followed by a rapid degeneration. The slow atrophy is induced by a decline in ecdysteroids. A neuropeptide, eclosion hormone (EH), is then released and triggers the rapid degeneration during which the fibers are fragmentized and absorbed (Schwartz and Truman, 1982, 1984). In the latter case, isolation of the abdomen prior to $\mathrm{EH}$ release prevents the rapid degeneration but the slow atrophy continues until the muscles eventually die (Schwartz and Truman, 1984). A similar phenomenon is seen in Drosophila that were neckligated at the $\mathrm{S}$ stage. Their muscle fibers broke down gradually, and the rapid fragmentation and absorption stage was not evident. In Manduca, by contrast, where the rapid degeneration is induced by the ecdysteroid decline, abdomen isolation accelerates muscle degeneration by causing a precocious decline in ecdysteroids. This response is not seen in Drosophila. Even when the flies were ligated between the thorax and abdomen at the $\mathrm{S}$ stage, the muscle breakdown was delaycd rather than accelerated. The similarity of the Drosophila response with that of A. polyphemus leads us to consider $\mathrm{EH}$ as a possible factor involved in inducing rapid muscle breakdown in Drosophila.

The ligation experiments indicate that a signal to induce the muscle breakdown in Drosophila appears prior to ecdysis at about the W stage. In Manduca, EH release occurs at about the time of completion of molting fluid resorption (Reynolds et al., 1979), a time corresponding to the onset of the W stage in Drosophila. A number of lines of evidence indicate that Drosophila has EH similar to moths (Truman and Kimura, unpublished). Immunohistochemistry using an antibody against $\mathrm{Man}_{-}$ duca EH (Copenhaver and Truman, 1986) stains a pair of cells in the brain of Drosophila that are homologous to known EH cells in Manduca. Also, injection of extracts of pharate adult heads or of the CNSs from wandering larvae of Drosophila score positive for EH activity in a Manduca larval ecdysis assay.

Conclusive evidence that muscle breakdown in A. polyphemus was triggered by $\mathrm{EH}$ came from inducing degeneration in isolated abdomens by purified preparations of this peptide (Schwartz and Truman, 1982, 1984). In Drosophila, however, we have not yet been able to induce muscle breakdown by the injection of extracts of pharate adult heads or CNSs of wandering larvae into neck-ligated flies or ligated abdomens. Thus, at this time, the case for EH regulating muscle degeneration in Drosophila remains circumstantial.

The methods of neck ligation and abdomen isolation differed in their effectiveness in preserving the muscles. In both instances ligation at the $\mathrm{W}$ stage or later did not prevent degeneration. Thus, both sets of data are consistent with the hypothesis that an anterior-derived signal occurring about $1-3 \mathrm{hr}$ before ecdysis serves as the trigger for muscle death. Abdomen ligation at earlier times appears to completely prevent the abdominal muscles from seeing the signal but neck ligation is less effective. One cxplanation of the difference is that an early head signal might be responsible for a second signal from the thorax at the $\mathrm{W}$ 
stage. An alternate possibility arises if $\mathrm{EH}$ is the trigger. Immunocytochemical studies show that the $\mathrm{EH}$ cells of Drosophila are in the brain but they project into the thorax where release presumably occurs (Truman, unpublished). Neck ligation may not be able to prevent some subsequent release of EH from the injured processes in the thorax.

An interesting aspect of cell death in Drosophila is that the control over neuronal degeneration differs from that for muscle death. Neuronal death is triggered after eclosion and is correlated with wing inflation behavior. This correlation is supported by both the behavior and ligation experiments reported here. Also, an uncharacterized mutant in Drosophila that does not expand its wings, but is otherwise a normal adult, shows reduced neuronal death similar to the confined flies (Kimura and Truman, unpublished). The tanning hormone, bursicon (Cottrell, 1962; Fraenkel and Hsiao, 1962), is usually released at the time of wing expansion and induces transient plasticization of the wings that facilitates their subsequent inflation (Truman and Endo, 1974). Bursicon triggers the postecdysial death of wing epidermal cells in a large fly, Lucilia cuprina (Seligman and Doy, 1973; Seligman et al., 1975), but it is not likely involved in causing neuronal death in Drosophila. This conclusion is based on Table 2, which shows that cuticular darkening, an event associated with bursicon action, is not correlated with normal neuronal death. In moths, other peptides besides bursicon are also released after eclosion. For example, in Manduca the cardioacceleratory peptides are released at this time to cause an increase in heart rate, directing blood into the thorax to aid in wing expansion (Tublitz and Truman, 1985a, b). We cannot exclude the possibility that a similar peptide might have a role in triggering neuronal death in Drosophila.

Besides hormonal factors, neural influences may also have a role in triggering neuronal death. In Manduca, forcing moths to show sustained digging behavior after eclosion will delay the death of some neurons (Truman, 1983). Also, for at least one of the neurons there is evidence that phasic descending input may be involved in triggering its degeneration (Fahrbach and Truman, 1987). In Drosophila the time course of neuronal death can also be modified by forcing the insect to dig. In this case, however, the neuronal death appears to be suppressed as long as the confinement continued. Thus, confinement not only suppresses subsequent events such as wing-spreading behavior and cuticular tanning (Cottrell, 1962) but also the appearance of the signal that induces neuronal death.

The effect of confinement on muscle degeneration in Drosophila is not as dramatic. The muscles become committed to breakdown by the signal that occurs around the $\mathrm{W}$ stage but apparently this death can be delayed for a few hours. This delay may be due to the sustained activity of the muscles and/or related motoneurons. In the giant silkmoth, chronic stimulation of motoneurons or enhancement of CNS activity with pharmacological agents causes the preservation of the corresponding muscles (Lockshin and Williams, 1965a, b). Under the constant confinement, digging activity decreases gradually as the fly ages (unpublished; Reid et al., 1987, in Sarcophaga bullata). The eventual onset of muscle breakdown in Drosophila that are continuously confined may be due to this waning of digging behavior.

Our studies suggest that the fly uses the different signals to induce the postmetamorphic death of the neurons and the muscles. In Manduca, the postecdysial death is triggered independently in the nervous and muscular systems although both use the same cue, the decline of ecdysteroids, to induce the death (Schwartz and Truman, 1983; Truman and Schwartz, 1984). In A. polyphemus, the muscle breakdown is induced by $\mathrm{EH}$ but the corresponding motoneurons do not then die after adult ecdysis (Schwartz and Truman, 1984). Thus, the mechanism of the induction of the cell death would have evolved independently in the nervous and muscular systems in each species.

\section{References}

Altman, J. S., and E. M. Bell (1973) A rapid method for the demonstration of nerve cell bodies in invertebrate central nervous systems. Brain Res. 63: 487-489.

Atkins, E. L. (1949) A study of the ptilinum and ptilinal musculature of the Pomace fly, Drosophila melanogaster Meigen (Diptera Drosophilidae). Ann. Ent. Soc. Am. 42: 245-257.

Bainbridge, S. P., and M. Bownes (1981) Staging the metamorphosis of Drosophila melanogaster. J. Embryol. Exp. Morphol. 66: 57-80.

Copenhaver, P. F., and J. W. Truman (1986) Identification of the cerebral neurosecretory cells that contain eclosion hormone in the moth Manduca sexta. J. Neurosci. 6: 1738-1747.

Cottrcll, C. B. (1962) The imaginal edysis of blowflies. The control of cuticular hardening and darkening. J. Exp. Biol. 39: 395-411.

Crossley, A. C. (1978) The morphology and development of the Drosophila muscular system. In The Genetics and Biology of Drosophila, M. Ashburner and T. R. F. Wright, eds., pp. 499-560, Academic, London.

Ellis, H. M., and H. R. Horvitz (1986) Genetic control of programmed cell death in the nematode, $C$. elegans. Cell 44: 817-829.

Ephrussi, B., and A. W. Beadle (1936) A technique of transplantation for Drosophila. Am. Naturalist 70: 218-225.

Fahrbach, S. E., and J. W. Truman (1987) Possible interactions of a steroid hormone and neural inputs in controlling the death of an identified neuron in the moth Manduca sexta. J. Neurobiol. 18:497508.

Fahrbach, S. E., and J. W. Truman (1988) Cycloheximide inhibits ecdysteroid-regulated neuronal death in the moth Manduca sexta. Soc. Neurosci. Abstr. 14: 368 .

Finlayson, L. H. (1975) Development and degeneration. In Insect Muscle, P. N. P. Usherwood, ed., pp. 75-149, Academic, New York.

Fraenkel, G. (1935) Observations and experiments on the blowfly (Calliphora erythrocephala) during the first day after emergence. Proc. Zool. Soc. Lond., 87: 893-904.

Fraenkel, G., and C. Hsiao (1962) Hormonal and nervous control of tanning in the fly. Science 138: 27-29.

Hamburger, V. (1975) Cell death in the development of the lateral motor column of the chick embryo. J. Comp. Neurol. 160: 535-546.

Hamburger, V., and R. W. Oppenheim (1982) Naturally occurring neuronal death in vertebrates. Neurosci. Comment 1: 39-55.

Hedgecock, E., J. E. Sulston, and N. Thompson (1983) Mutations affecting programmed cell deaths in the nematode Caenorhabdites elegans. Science 220: 1277-1280.

Lawrence, P. A., and P. Johnston (1984) The genetic specification of pattern in a Drosophila muscle. Cell 36: 775-782.

Lockshin, R. A. (1969) Programmed cell death. Activation of lysis by a mechanism involving synthesis of protein. J. Insect Physiol. 15: $1505-1516$.

Lockshin, R. A., and C. M. Williams (1965a) Programmed cell death III. Neural control of the breakdown of the intersegmental muscles of silkmoths. J. Insect Physiol. 11: 601-610.

Lockshin, R. A., and C. M. Williams (1965b) Programmed cell death IV. The influence of drugs on the breakdown of the intersegmental muscles of silkmoths. J. Insect. Physiol. 11: 803-809.

Martin, D. P., R. E. Srhmidt, P. S. DiStefano, O. H. Lowry, J. G. Carter, and E. M. Johnson (1988). Inhibitors of protein synthesis and RNA synthesis prevent neuronal death caused by nerve growth factor deprivation. J. Cell Biol. 106: 829-844.

Miller, A. (1950) The internal anatomy and histology of the imago of Drosophila melanogaster. In Biology of Drosophila, M. Demerec, ed., pp. 420-534, Wiley, New York.

Nordeen, E. J., K. W. Nordeen, D. R. Sengelaub, and A. P. Arnold (1985) Androgens prevent normally occurring cell death in a sexually dimorphic spinal nucleus. Science 229: 671-673.

O'Leary, D. D. M., J. W. Fawcett, and W. M. Cowan (1986) Topo- 
graphic targeting errors in the retinocollicular projection and their elimination by selective ganglion cell death. J. Neurosci. 6: 36923705.

Oppenheim, R. W., and D. M. Prevette (1988) Reduction of naturally occurring neuronal death in vivo by the inhibition of protein and RNA synthesis. Soc. Neurosci. Abstr. 14: 368.

Reid, S. N. M., G. Fraenkel, and S. Friedman (1987) Extrication, the primary event in eclosion, and its relationship to digging, pumping and tanning in Sarcophaga bullata. J. Insect Physiol. 33: 339-348.

Reynolds, S. E., P. H. Taghert, and J. W. Truman (1979) Eclosion hormone and bursicon titres and the onset of hormonal responsiveness during the last day of adult development in Manduca sexta (L). J. Exp. Biol. 78: 77-86.

Schwartz, L. M., and B. K. Kay (1987) De novo transcription and translation of new genes is required for the programmed death of the intersegmental muscles of the tobacco hawkmoth. Soc. Neurosci. Abstr. 13: 8 .

Schwartz, L. M., and J. W. Truman (1982) Peptide and steroid regulation of muscle degeneration in an insect. Science 215: 1420-1421.

Schwartz, L. M., and J. W. Truman (1983) Hormonal control of rates of metamorphic development in tobacco hornworm Manduca sexta. Dev. Biol. 99: 103-114.

Schwartz, L. M., and J. W. Truman (1984) Hormonal control of muscle atrophy and degeneration in the moth Antheraea polyphemus. J. Exp. Biol. 111: 13-30.

Seligman, I. M., and F. A. Doy (1973) Hormonal regulation of disaggregation of cellular fragments in the haemolymph of $\mathrm{Lucilia} \mathrm{Cu}$ prina. J. Insect Physiol. 19: 125-135.
Seligman, I. M., B. K. Filshie, F. A. Doy, and A. C. Crossley (1975) Hormonal control of morphogenetic cell death of the wing hypodermis in Lucilia cuprina. Tissue Cell 7: 281-296.

Spreij, Th. E. (1971) Cell death during the development of the imaginal disks of Calliphora erythrocephala. Neth. J. Zool. 21: 221-264.

Truman, J. W. (1973) Physiology of insect ecdysis. III. Relationship between the hormonal control of eclosion and of tanning in the tobacco hornworm, Manduca sexta. J. Exp. Biol. 58: 821-829.

Truman, J. W. (1983) Programmed cell death in the nervous system of an adult insect. J. Comp. Neurol. 216: 445-452.

Truman, J. W. (1984) Cell death in invertebrate nervous system. Annu. Rev. Neurosci. 7: 171-188.

Truman, J. W., and P. T. Endo (1974) Physiology of insect ecdysis. Neural and hormonal factors involved in wing spreading behavior of moths. J. Exp. Biol. 61: 47-55.

Truman, J. W., and L. M. Schwartz (1984) Steroid regulation of neuronal death in the moth nervous system. J. Neurosci. 4: 274-280.

Tublitz, N. J., and J. W. Truman (1985a) Insect cardioactive peptides. I. Distribution and molecular characterization of two cardioacceleratory peptides (CAP) in the tobacco hawkmoth, Manduca sexta. J. Exp. Biol. 114: 365-379.

Tublitz, N. J., and J. W. Truman (1985b) Insect cardioactive peptides. II. Neurohormonal control of heart activity by two cardioacceleratory peptides in the tobacco hawkmoth, Manduca sexta. J. Exp. Biol. 114: 381-395.

Williams, R. W., and K. Herrup (1988) The control of neuron number. Annu. Rev. Neurosci. 11: 423-453. 